\section{Differences in competition statistics between winners and losers in male and female tennis players} in Olympic Games

Ángel Iván Fernández-García ${ }^{1}$, Juan Carlos Blanca-Torres² ${ }^{2}$ Pantelis Theodoros Nikolaidis³ and Gema Torres-Luque ${ }^{2}$

${ }^{1}$ University of Zaragoza, Faculty of Health and Sport Science, Zaragoza, Spain. (E-mail: angelivanfg@hotmail.com)

${ }^{2}$ University of Jaén, Faculty of Humanities and Education Science, Jaén, Spain (E-mail: jcblancatorres@gmail.com; gtluque@ujaen.es)

${ }^{3}$ Exercise Physiology Laboratory, Nikaia, Greece

(E-mail: pademil@hotmail.com)
Comentado [U1]: What are the most determinant variables to achieve victory in male and female tennis matches in Olympic

Games?

Correspondence author:

Gema Torres-Luque

Universidad de Jaén

Campus Las Lagunillas s/n

23071 Jaén

Mail: gtluque@ujaen.es

\title{
Abstract
}

The aim of this study was to examine differences in the performance indicators between winners and losers in male and female high-level tennis players. One hundred twenty-eight tennis singles matches played on grass court surface of London 2012 Olympic Games were analyzed. Data were collected from the official website of the Olympics and the following groups of variables were analyzed: serve variables $(n=7)$, serve return variables $(n=3)$ and game related variables $(n=5)$. The results showed that winners had greater $(\mathrm{p}<0.05)$ values of second serve $(\%)$, aces, first and second serve points won $(\%)$, points won on first and second serve return (\%), break points played and break points won (\%). Furthermore, they get more, winners with both groundstrokes and net points won (\%) than losers in both sexes. Furthermore, losers committed more doubles faults than winners, and in male category more unforced errors, whereas female winners get higher serve maximum speed $(\mathrm{p}<0.05)$. Performance indicators according to the result of the match predicted that break points won, first serve points won (\%) and first serve return points won $(\%)$ are the most relevant variables in males $(\mathrm{SC}=.434$; $\mathrm{SC}=.340$; $\mathrm{SC}=.327$ ), whereas it was the break points won ( $\mathrm{SC}=-.372$ ) in females. Therefore, coaches should consider the variation of the competition statistics by gender if they want enhance the chances of success of their players.

Keywords: notational analysis, match analysis, racquet sports, performance indicators. 


\section{INTRODUCTION}

Tennis is an open-skill sport in which players constantly make tactical decisions related to specific game situations (Filipcic, Zecic, Reid, Crespo, Panjan, \& Nejc, 2015). Players plan strategies to maximize their chances of winning a match based on knowledge of their own strengths and weaknesses as well as those of their opponent and taking contextual and environmental factors (climate, surface, tournament round, opponent level...) into consideration (Cui, Gómez, Gonçalves, Liu, \& Sampaio, 2017; Varas Caro \& Gómez Ruano, 2016). Thus, the ATP (Association of Tennis Professional) updates weekly information about players and competition statistics (Reid, McMurtrie, \& Crespo, 2010).

The examination of match statistics or performance indicators in professional tennis is attracting increasing research attention (Cui, Gómez, Gonçalves, \& Sampaio, 2018; Fitzpatrick, Stone, Choppin, \& Kelley, 2019; Klaus, Bradshaw, Young, O’Brien, \& Zois, 2017; Martin, Bideau, Touzard, \& Kulpa, 2019). These studies provide information about the way the game is played on different surfaces (Cui et al., 2018), or allow us understanding the differences between players of different levels (Hizan, Whipp, \& Reid, 2011; Klaus et al., 2017; Söğüt, 2017) or genders (R Cross, 2014; Hizan, Whipp, \& Reid, 2015; Stare, Zibrat, \& Filipcic, 2015). Investigating the statistical analysis of game characteristics, we can identify the reasons for winning or losing a game (Filipčič, Filipčič, \& Berendijaš, 2008; Fitzpatrick et al., 2019). In this sense, the performance indicators in Grand Slam have been fundamentally researched (Martin et al., 2019; Reid, Morgan, \& Whiteside, 2016). These studies observed that one of the main differences is related with the service performance.

However, although there are studies that analyze competition statistics, almost have it done with Grand Slam matches that are played at best of five sets and as has been shown in previous studies, competition statistics change throughout the sets, so it could be possible that there are differences in performances indicators between matches to the best of five sets with regard to the best of three (Martin et al., 2019). In addition, there are no references - to the best of our knowledge - which focus on statistical differences between winners and losers in both genders and only one did it on grass surface but only in male players.

These type of analyses are interesting for two main reasons, on the one hand, the Olympic Games is the most important world competition and the best of three sets is played. On the other, male and female professional tennis have technical-tactical differences (Rod Cross, 2014; Filipčič et al., 2008; Hizan et al., 2011; Reid et al., 2016) due in part to the physical players profiles of both genders (Munivrana, Filipčić, \& Filipčić, 2015; Myburgh, Cumming, Coelho E Silva, Cooke, \& Malina, 2016). Therefore, the competition analysis provides valuable information which allows defining the technicaltactical demands of the game for the players (O'Donoghue \& Ingram, 2001). In this way, the main purpose of the present study is to identify the performance indicators in relation to gender during the full matches of London 2012 Olympic Games played in grass surface.

\section{METHOD}

\section{Sample}

Data of 176 players performing of 128 London Olympic Games matches were collected, 64 from male and 64 from female players. All of them were played in grass court surface and proceeded from the first round until the final. The matches which had an early retirement, disqualification of some player or without IBM system (IBM: Armonk, NY, U.S.A) in the court were excluded. This occurred in a total of two times, both in female players.

\section{Procedure}

The data were collected from the official website of London Olympic Games (https://www.olympic.org/london-2012) . All the matches were played at the best of three sets in accordance with ITF (International Tennis Federation) rules (ITF, 2017). Intra-rater reliability was calculated through observer registering the same values of play (two game) on two occasions separated by a four-week period. Cohen's Kappa was used and 0.95 was obtained for observer. The value was considered as very good (>0.80) (Landis \& Koch, 1977). 
The variables analyzed were divided into five groups: temporary variables, variables related with serve performance, variables related with the return-serve performance, variables related with net play performance and variables related with winners and unforced errors (Table 1).

Table 1. Dependent variables analyzed

\begin{tabular}{|c|c|}
\hline Variable & Description \\
\hline \multicolumn{2}{|l|}{ Temporary variables } \\
\hline Match time & Total match time in minutes \\
\hline \multicolumn{2}{|l|}{ Variables related to serve } \\
\hline Aces & Number of direct serves \\
\hline Doubles faults & Number of doubles faults \\
\hline First serve in (\%) & $\begin{array}{l}\text { Number of first serve in } \div \text { Number of points play at first } \\
\text { serve }\end{array}$ \\
\hline Second serve in (\%) & $\begin{array}{l}\text { Number of second serve in } \div \text { Number of points play at } \\
\text { second serve }\end{array}$ \\
\hline First serve points won (\%) & $\begin{array}{l}\text { Number of points won with first serve } \div \text { Number of points } \\
\text { play with first serve }\end{array}$ \\
\hline Second serve points won (\%) & $\begin{array}{l}\text { Number of points won with second serve } \div \text { Number of } \\
\text { points play with second serve }\end{array}$ \\
\hline Serve Maximum Speed & The highest serve velocity \\
\hline \multicolumn{2}{|l|}{ Variables related to returns } \\
\hline Return of first serve points won (\%) & $\begin{array}{l}\text { Number of points won on first serve return } \div \text { Number of } \\
\text { points play at first serve return }\end{array}$ \\
\hline Return of second serve points won (\%) & $\begin{array}{l}\text { Number of points won on second serve return } \div \text { Number of } \\
\text { points play at second serve return }\end{array}$ \\
\hline Break points & Total break points \\
\hline Breaks & Break points won \\
\hline Break points won (\%) & Break points won $\div$ Break points played \\
\hline $\begin{array}{l}\text { Variables related with net play } \\
\text { performance }\end{array}$ & \\
\hline Net points won (\%) & $\begin{array}{l}\text { Number of points won at the net } \div \text { Number of points play } \\
\text { at the net }\end{array}$ \\
\hline \multicolumn{2}{|c|}{$\begin{array}{l}\text { Variables related to winners and unforced } \\
\text { errors }\end{array}$} \\
\hline Winners & Total winners \\
\hline Forehand winners & Total forehand winners \\
\hline Backhand winners & Total backhand winners \\
\hline Unforced errors & Total unforced errors \\
\hline
\end{tabular}

The data were collected in a specifically designed spreadsheet (Microsoft Excel) and were the exported to the SPSS 22.0 statistical program for analysis. Data were analysed by set.

\section{Statistical Analysis}

IBM SPSS version 22.0 (IBM Corp., Armonk. NY. USA) statistical program for analysis was used. A descriptive analysis of the data (means and standard deviation) in male and female independently was conducted. A univariate (Mann Whitney U) test (non-parametric) was carried out analyzing the differences between winning and losing players, because the assumptions of normality and homogeneity of variances were not satisfied. To identify those statistical variables that best differentiate the two groups (winning and losing players), a discriminant analysis (Ntoumanis, 2001) was conducted. For the interpretation of the linear vectors, a Structural Coefficient (SC) $>0.30$ was considered relevant. Significance was set at $\mathrm{p}<0.05$.

RESULTS

The differences between winning and losing male and female gender are shown in table 2 . 
Table 2. Differences between winning and losing male and female players

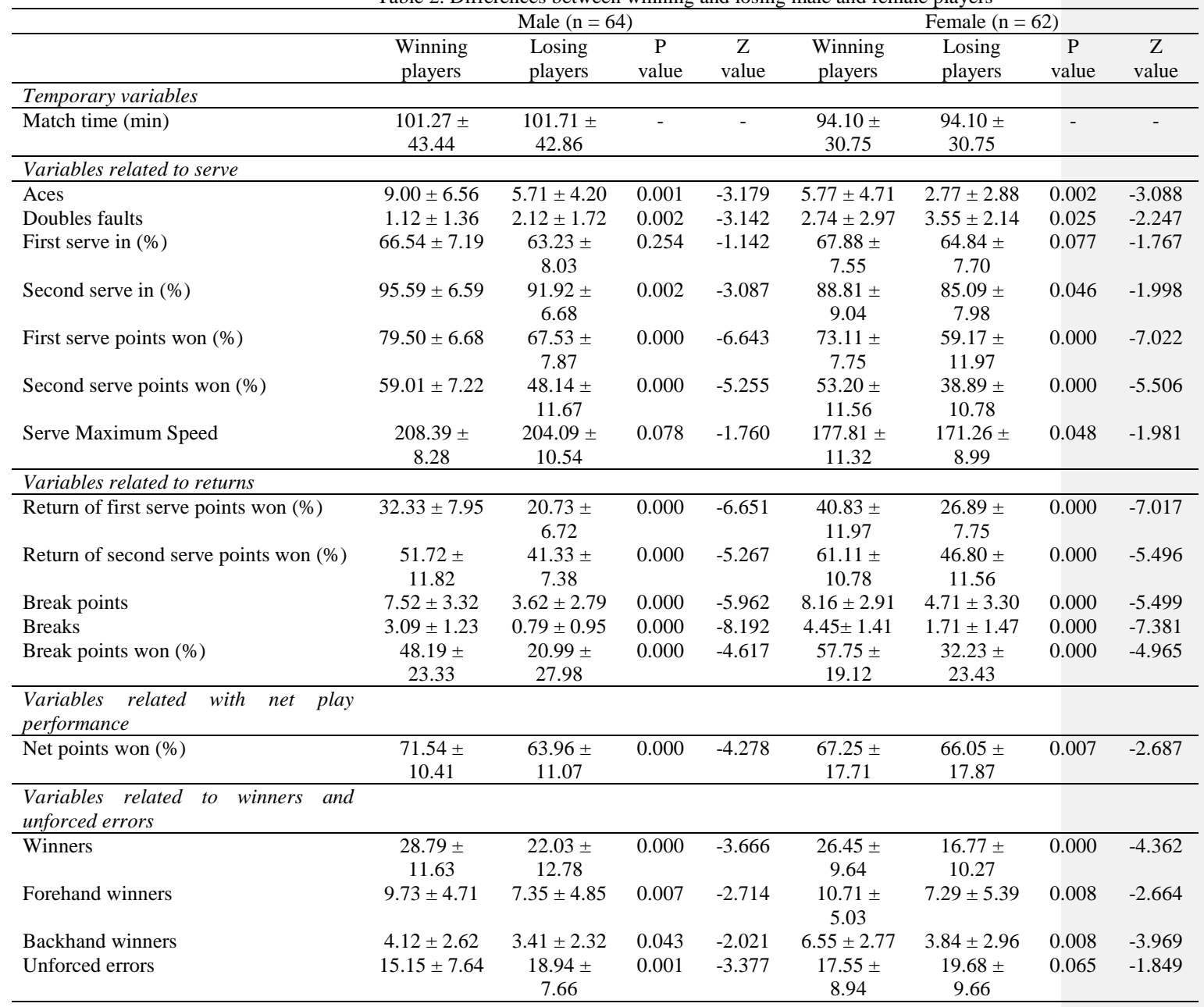

2 The results showed that in both genders, winners had higher values in aces $(\mathrm{p}<0.005)$, points won with first and second serve $(\%)(p<0.001)$, percentage of second serve in $(p<0.05)$ and committed less doubles faults $(\mathrm{p}<0.05)$. On other hand, with the return, winner players won more points with their second serve $(\%)$, have more break points, get more breaks and won more break points $(\%)(\mathrm{p}<0.001)$ and net points $(\%)(\mathrm{p}<0.05)$. Furthermore, they get more overall winners $(\mathrm{p}<0.001)$ than losing players and get more winners with their forehand $(p<0.001)$ and backhand $(p<0.05)$ too. Furthermore, males have lower value of unforced errors than losing players $(\mathrm{p}<0.005)$ while female winners have a greater values of maximum serve speed $(\mathrm{p}<0.05)$.

Table 3 and 4 shown the discriminant analysis from both genders for winning and losing players. The obtained function was significant for both genders $(\mathrm{p}<0.001)$ and classify correctly the $98.5 \%$ of the cases in male tennis and the $96.8 \%$ in female tennis.

Table 3. Standardised coefficients from the discriminant analysis of the game statistics betwenn winning and lossing male players 


\begin{tabular}{lc}
\hline & Winning-Losing \\
\hline Break points won (\%) & .434 \\
First serve points won (\%) & .340 \\
Serve return of first serve points won (\%) & .327 \\
Break points & .264 \\
Second serve points won (\%) & .231 \\
Serve return of second serve points won (\%) & .219 \\
Break points won (\%) & .219 \\
Net points won (\%) & .146 \\
Doubles faults & -.133 \\
Aces & .124 \\
Winners & .115 \\
Second serve in (\%) & .114 \\
Forehand winners & .103 \\
Unforced errors & -.103 \\
Serve Maximum Speed & .094 \\
First serve in (\%) & .090 \\
Backhand winners & .059 \\
Match time (min) & -.002 \\
\hline Eigenvalue & 5.995 \\
Wilks'Lambda & .143 \\
Canonical correlation & .926 \\
Chi-square & 101.149 \\
Significance & $<.001$ \\
Reclassification & $98.5 \%$ \\
\hline *SC: Structural Coeficient. discriminant value $\geq 0.30$ & \\
& \\
\hline
\end{tabular}

*SC: Structural Coeficient discriminant value $>0.30$

As can be seen in the results, the most powerful discriminators between winning and losing in male were break points won (\%) (SC=,434), first serve points won (\%) $(\mathrm{SC}=, 340)$ and serve return of first serve points won $(\%)(\mathrm{SC}=, 327)$.

Table 4. Standardised coefficients from the discriminant analysis of the game statistics betwenn winning and lossing female players

\begin{tabular}{lc}
\hline & Female \\
\hline & Winning-Losing \\
\hline Break points won (\%) & -.372 \\
First serve points won (\%) & -.270 \\
Serve return of first serve points won (\%) & -.270 \\
Second serve points won (\%) & -.250 \\
Serve return of second serve points won (\%) & -.250 \\
Break points won (\%) & -.233 \\
Break points & -.216 \\
Winners & -.189 \\
Backhand winners & -.185 \\
Aces & -.150 \\
Forehand winners & -.128 \\
Serve Maximum Speed & -.125 \\
Second serve in (\%) & -.085 \\
First serve in (\%) & -.078 \\
Doubles faults & .061 \\
Unforced errors & .045 \\
Net points won (\%) & -.013 \\
Match time (min) & $<.001$ \\
\hline Eigenvalue & 6.792 \\
Wilks'Lambda & .128 \\
Canonical correlation & .934 \\
Chi-square & 96.496 \\
Significance & $<.001$ \\
Reclassification & $96.8 \%$ \\
\hline *SC: Structural Coeficient. discriminant value $\geq 0.30$ &
\end{tabular}


As can be seen in the results, the most powerful discriminators between winning and losing in female were break points won (\%) (SC= -372).

\section{DISCUSSION}

Match statistics aid improving the quality of tennis training programs (Kovacs, 2007; Lago-Peñas, Lago-Ballesteros, Dellal, \& Gómez, 2010; Ortega, Villarejo, \& Palao, 2009). They allow to know what happens specifically in the competition and help coaches to adjust specific training goals according to factors like gender, surface, category of players or moment of the match (Cui et al., 2018; Meffert, O’Shannessy, Born, Grambow, \& Vogt, 2018; Reid et al., 2016; Stare et al., 2015; Varas Caro \& Gómez Ruano, 2016). Nevertheless, nowadays there was no criterion about the variables that differentiate winners and losers in grass courts surface in both genders in matched played to the best of three sets. In this sense, this study shows how in male players the indicators that differentiate winner than loser are the break points won, percentage of points scored with the first service and points scored with the serve return after opponent first service, while in female players, the determinant are the break points.

As previous studies concluded, serve and return are the most determinant skills in tennis performance (Gillet, Leroy, Thouvarecq, \& Stein, 2009). Our study show that independent of gender, winners have better values in almost of these variables like aces, points won with first and second serve (\%), less doubles faults and get higher percentage of second serve in (\%) in grass court surface. It could be associated with a better control of serve effects and direction (Gillet et al., 2009). In male tennis, these results are in accordance with Katić, Milat, Zagorac, and Đurović (2011) for the same surface, although this study found in addition higher percentages of first serves in. Other studies support our finding but find better performance of first serve in (\%) in winner players too, although their sample were played on clay surface (Filipčič et al., 2008) or the data provided of all Grand Slams (Ma, Liu, Tan, \& Ma, 2013). In female tennis, the results are in accordance with Filipčič et al. (2008) in almost variables except, aces and percentage of first serve in, in which they don't found any differences between winners and losers. However, previous results were founded in clay surface, so it should be considered because surface affects match statistics (Cui et al., 2018; Reid et al., 2016).

Regarding with serve maximum speed, although O’Donoghue and Ballantyne (2004) found a strong relationship between serve speed and the probability of winning the point in male tennis, it is seems that these variable it is not determinant for the match final outcome in neither of two genders. Katić et al. (2011) obtained the same results for men in grass court surfaces but furthermore, they did not appreciate differences in the average speed of first and second serve. No studies have been found to compare our results of female players.

With regard to the return variables, winners have better results than losers, highlighting the great role of this stroke in the modern professional tennis (Ma et al., 2013). These values are also similar with the obtained by other studies in males for grass courts (Katić et al., 2011) and for all surfaces (Ma et al., 2013). On the other hand Filipčič et al. (2008) arrived to the same conclusion for both genders in clay surface. As it seems to happen with our results, other studies find better performance with the return stroke in female than male players and Reid et al. (2016) conclude that women contacted the ball closer to the net when they returned in hard court surface, so it could be associated with a more offensive strategy when they returned. On other hand, Gillet et al. (2009) found that in male tennis, the most beneficial zone for place the serve return it is the central zone for the first and second serve in clay court surface, so it would be interesting to study it in grass courts in both genders. In addition, both men and women winners, get better values of break points won (\%) like others researchers in grass (Katić et al., 2011) and all Grand Slam surfaces for men (Ma et al., 2013) and in clay for women (Filipčič et al., 2008). Nevertheless, although the study of Filipčič et al. (2008) was develop on clay court surfaces, it seems to be surprising that they did not find differences in men for break points won between winners and losers.

With net points, winners have better performances, but it is surprising that only men losers committed more unforced errors than winners, whereas the rest of studies get differences in this variable between winners and losers independent of surface and gender (Filipčič et al., 2008; Hizan et al., 2011; Katić et al., 2011). 


\begin{abstract}
According with our results it could be affirmed that winners seem to be more offensive (get more aces and winners) and safer (less doubles faults) than losers. Considering all the variables studied, break points won (\%) was the most determinant variable to win the match in both genders. Probably, it could be because winners have a stronger mentality than losers in the most decisive moments of a match and as Meffert et al. (2018) concluded for Wimbledon tournaments in male category, winning players keep up their first serve in percentage of points at break points, while losing players serve a lower percentage. It is worth mentioning that these results show the situation on a grass surface and in matches to the best of three sets, therefore future studies are needed to increase the knowledge of tennis performance, especially in female tennis, as well as to extend to another categories and surfaces.
\end{abstract}

\title{
CONCLUSIONS
}

This study demonstrated that players had different performance statistic depending on gender in grass court surface in a best of three matches. Furthermore winners being more offensive and safer than losers, andiIndependent of gender, the most determinant variable to win the match was break points won (\%) and also first serve points won (\%) and return of first serve points won (\%) in males. These results could be used as a reference by coaches to improve training programs for competitive players.

\section{PRACTICAL APPLICATION}

Get and analyze match statistics could be useful for coaches to set specific training goals and enhance competitive performance. Nonetheless, very few players have an analyst in their staffs or have a coach who records the competition data. Probably, it could seem a hard and complex task, but nowadays there are lots of easy apps with which to obtain the results automatically without statistical analysis, just entering the data. In addition to improve trainings programs, it can let to know the own and opponent weaknesses and strengths.

\section{REFERENCES}

Cross, R. (2014). Men's tennis vs Women's tennis. ITF Coaching and Sport Science Review, 62, 3-5.

Cross, R. (2014). Men's tennis vs Women's tennis. ITF Coaching and Sport Science Review, 62(22), 3-5.

Cui, Y., Gómez, M.-Á., Gonçalves, B., Liu, H., \& Sampaio, J. (2017). Effects of experience and relative quality in tennis match performance during four Grand Slams. International Journal of Performance Analysis in Sport, 17(5), 783-801.

Cui, Y., Gómez, M.-Á., Gonçalves, B., \& Sampaio, J. (2018). Performance profiles of professional female tennis players in grand slams. PloS one, 13(7), e0200591.

Filipčič, T., Filipčič, A., \& Berendijaš, T. (2008). COMPARISON OF GAME CHARACTERISTICS OF MALE AND FEMALE TENNIS PLAYERS AT ROLAND GARROS 2005. Acta Universitatis Palackianae Olomucensis. Gymnica, 38(3).

Fitzpatrick, A., Stone, J. A., Choppin, S., \& Kelley, J. (2019). A simple new method for identifying performance characteristics associated with success in elite tennis. International Journal of Sports Science \& Coaching, 14(1), 43-50.

Gillet, E., Leroy, D., Thouvarecq, R., \& Stein, J.-F. (2009). A notational analysis of elite tennis serve and serve-return strategies on slow surface. The Journal of Strength \& Conditioning Research, 23(2), 532-539.

Hizan, H., Whipp, P., \& Reid, M. (2011). Comparison of serve and serve return statistics of high performance male and female tennis players from different age-groups. International Journal of Performance Analysis in Sport, 11(2), 365-375. 
Hizan, H., Whipp, P., \& Reid, M. (2015). Gender differences in the spatial distributions of the tennis serve. International Journal of Sports Science \& Coaching, 10(1), 87-96.

Katić, R., Milat, S., Zagorac, N., \& Đurović, N. (2011). Impact of game elements on tennis match outcome in Wimbledon and Roland Garros 2009. Collegium antropologicum, 35(2), 341-346.

Klaus, A., Bradshaw, R., Young, W., O’Brien, B., \& Zois, J. (2017). Success in national level junior tennis: Tactical perspectives. International Journal of Sports Science \& Coaching, 12(5), 618-622.

Kovacs, M. S. (2007). Tennis physiology. Sports Medicine, 37(3), 189-198.

Lago-Peñas, C., Lago-Ballesteros, J., Dellal, A., \& Gómez, M. (2010). Game-related statistics that discriminated winning, drawing and losing teams from the Spanish soccer league. Journal of sports science \& medicine, 9(2), 288.

Landis, J. R., \& Koch, G. G. (1977). The measurement of observer agreement for categorical data. biometrics, 159-174.

Ma, S.-M., Liu, C.-C., Tan, Y., \& Ma, S.-C. (2013). Winning matches in Grand Slam men's singles: An analysis of player performance-related variables from 1991 to 2008. Journal of sports sciences, 31(11), 1147-1155.

Martin, C., Bideau, B., Touzard, P., \& Kulpa, R. (2019). Identification of serve pacing strategies during five-set tennis matches. International Journal of Sports Science \& Coaching, 14(1), 32-42.

Meffert, D., O'Shannessy, C., Born, P., Grambow, R., \& Vogt, T. (2018). Tennis serve performances at break points: Approaching practice patterns for coaching. European Journal of Sport Science, 18(8), 1151-1157.

Munivrana, G., Filipčić, A., \& Filipčić, T. (2015). Relationship of speed, agility, neuromuscular power, and selected anthropometrical variables and performance results of male and female junior tennis players. Collegium antropologicum, 39(Supplement 1), 109-116.

Myburgh, G. K., Cumming, S. P., Coelho E Silva, M., Cooke, K., \& Malina, R. M. (2016). Growth and maturity status of elite British junior tennis players. Journal of sports sciences, 34(20), 1957-1964.

O'Donoghue, P., \& Ingram, B. (2001). A notational analysis of elite tennis strategy. Journal of sports sciences, 19(2), 107-115.

O'Donoghue, P., \& Ballantyne, A. (2004). The impact of speed of service in Grand Slam singles tennis. Paper presented at the Science and Racket Sports III: The Proceedings of the Eighth International Table Tennis Federation Sports Science Congress and the Third World Congress of Science and Racket Sports.

Ortega, E., Villarejo, D., \& Palao, J. M. (2009). Differences in game statistics between winning and losing rugby teams in the Six Nations Tournament. Journal of sports science \& medicine, 8(4), 523.

Reid, M., McMurtrie, D., \& Crespo, M. (2010). Title: The relationship between match statistics and top 100 ranking in professional men's tennis. International Journal of Performance Analysis in Sport, 10(2), 131-138.

Reid, M., Morgan, S., \& Whiteside, D. (2016). Matchplay characteristics of Grand Slam tennis: implications for training and conditioning. Journal of sports sciences, 34(19), 1791-1798. 
Söğüt, M. (2017). A Comparison of Serve Speed and Motor Coordination between Elite and Club Level Tennis Players. Journal of Human kinetics, 55(1), 171-176.

Stare, M., Zibrat, U., \& Filipcic, A. (2015). STROKE EFFECTIVNESS IN PROFESSIONAL AND JUNIOR TENNIS/UCINKOVITOST UDARCEV V PROFESIONALNEM IN MLADINSKEM TENISU. Kinesiologia Slovenica, 21(2), 39.

Varas Caro, I., \& Gómez Ruano, M. Á. (2016). Análisis notacional en jugadores de tenis de élite en función de las variables contextuales. Kronos, 15(1). 